\title{
Commentary: Quality of life following aortic valve replacement in era of transcatheter approach: Change of time
}

\author{
Denis A. Berdajs, MD
}

From the Department of Cardiac Surgery, University Hospital Basel, Basel, Switzerland.

Disclosure: Author has nothing to disclose with regard to commercial support.

Received for publication Oct 9, 2019; revisions received Oct 9, 2019; accepted for publication Oct 10, 2019; available ahead of print Oct 24, 2019.

Address for reprints: Denis A. Berdajs, MD, Department of Cardiac Surgery, University Hospital Basel, Spitalstrasse 21, CH-4031 Basel, Switzerland (E-mail: denis.berdajs@bluewin.ch).

J Thorac Cardiovasc Surg 2021;161:1211-2

$0022-5223 / \$ 36.00$

Copyright (c) 2019 by The American Association for Thoracic Surgery

https://doi.org/10.1016/j.jtcvs.2019.10.054

With increasing life expectancy and the upward tick of aging in the populations of Western countries, aortic valve stenosis has become one of the most common structural heart valvular diseases, and the incidence of aortic valve stenosis is increasing. An estimated 4.2 to 5.6 million adults in the United States have some form of clinically important valve disease. ${ }^{1}$

There were approximately 40 million persons aged 65 and older in 2010, but this number is expected to be 55 million in 2020 and 72 million in $2030 .^{2}$ Because the common forms of valve diseases are linked to aging, this demographic shift will increase the number of patients with aortic stenosis. The Helsinki Aging Study, an echocardiographic screening study, provided further evidence of increased calcification and degeneration of the aortic valve with increasing age. Some degree of valvular calcification was noted in $75 \%$ of people aged 85 to 86 years. The prevalence of critical aortic valve stenosis increased with age from between $1 \%$ and $2 \%$ in persons aged 75 to 76 years to $6 \%$ in those aged 85 to 86 years. $^{3}$

The treatment of choice in symptomatic patients with severe aortic stenosis is aortic valve replacement (SAVR), where the perioperative risk may be evaluated based on comorbidities. ${ }^{4,5}$ However, all patients considered for aortic valve replacement should be evaluated by a heart team to determine suitability for a surgical versus a transcatheter approach. A transcatheter approach is considered primarily in patients with prohibitive, high, or intermediate surgical risk based on current guidelines. ${ }^{6}$ Recently, transcatheter aortic valve implementation (TAVR) has also emerged as viable alternative in patients with aortic stenosis who are at low risk. However, the promising results in regards to a few short-term studies on TAVI, as well as on SAVR, create the need for a scientific inquiry into quality-of-life postintervention. Ultimately, the aim of surgical or cardiological intervention is not only to resolve the structural heart disorder but to ascertain an acceptable quality of life and achieve a considerable life expectancy.

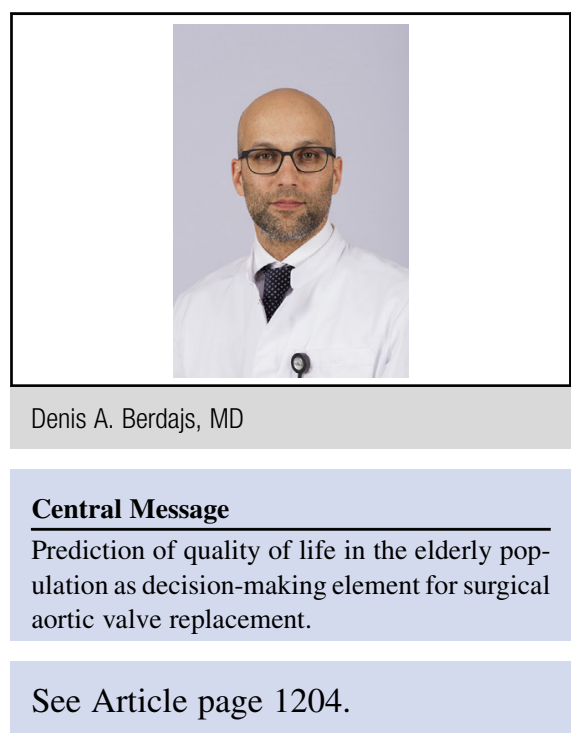

Blokzijl and colleagues ${ }^{7}$ recently conducted a prospective study that looked at quality of life following SAVR and patient stratification in accordance with age. It is important to pay attention to quality of life, independently of age, and to include the mental as well as physical quality of life. Although their cohort of 899 patients as such is not unique, in the final analysis, cases with combined interventions such as SAVR and coronary bypass intervention were included. In regard to age differences, elderly patients, especially those older than 80 years of age, had a certain decline in quality of life. This was independent of whether a concomitant procedure was performed.

The recent study has an important take-home message, especially in an era in which the decision making for TAVR versus SAVR, especially in low- and intermediaterisk patients, is increasingly ambiguous. In recently presented data for the European Association for Cardio-Thoracic Surgery in Lisbon, Portugal, as well for Transcatheter Cardiovascular Therapeutics in San Francisco, California, for the PARTNER 2 (Placement of Aortic Transcatheter Valves 2) trial, the mid-term results in regard to the mortality the SAVR showed a statistically significant better outcome. The impact of repeated interventions, effect of pacemaker implantation at mid-term, as well a greater stroke rate as an endpoint were yet to be presented. 
Importantly, when decision making by a heart team is undertaken, the team needs to evaluate both the recent risk profile of the individual case and also take into account the impact of intervention on late quality of life. Here, besides the age, which in a recent study was shown as an independent factor, the impact of stroke and risk of pacemaker implantation should be discussed.

\section{References}

1. Nkomo VT, Gardin JM, Skelton TN, Gottdiener JS, Scott CG, Enriquez-Sarano M. Burden of valvular heart diseases: a population-based study. Lancet. 2006;368: 1005-11.

2. Thaden JJ, Nkomo VT, Enriquez-Sarano M. The global burden of aortic stenosis. Prog Cardiovasc Dis. 2014;56:565-71.
3. Lindroos M, Kupari M, Heikkilä J, Tilvis R. Prevalence of aortic valve abnormalities in the elderly: an echocardiographic study of a random population sample. $J$ Am Coll Cardiol. 1993;21:1220-5.

4. Nishimura RA, Otto CM, Bonow RO, Carabello BA, Erwin JP III, Guyton RA, et al. 2014 AHA/ACC Guideline for the Management of Patients with Valvular Heart Disease: executive summary; a report of the American College of Cardiology/American Heart Association Task Force on Practice Guidelines. Circulation. 2014;129:2440-92 [published correction appears in Circulation. 2014;129:e650].

5. Kanwar A, Thaden JJ, Nkomo VT. Management of patients with aortic valve stenosis. Mayo Clin Proc. 2018;93:488-508.

6. Nishimura RA, Otto CM, Bonow RO, Carabello BA, Erwin JP III, Fleisher LA, et al. 2017 AHA/ACC focused update of the 2014 AHA/ACC Guideline for the Management of Patients With Valvular Heart Disease: a report of the American College of Cardiology/American Heart Association Task Force on Clinical Practice Guidelines. Circulation. 2017;135:e1159-95.

7. Blokzijl F, Houterman S, van Straten BHM, Daeter E, Brandon Bravo Bruinsma GJ, Dieperink W, et al. The impact of surgical aortic valve replacement on quality of life-a multicenter study. J Thorac Cardiovasc Surg. 2021;161: 1204-10.e7. 